\title{
Professional development of education managers in modern reality: psychological resources and risks
}

\author{
Tatyana Shcherbakova ${ }^{1 *}$, Dinamutdin Misirov $^{2}$, Vladimir Kirik ${ }^{2}$, and Irina Loseva ${ }^{2}$ \\ ${ }^{1}$ Rostov Institute of advanced training and professional retraining of education workers, \\ 344041 Rostov-on-Don, Russian Federation \\ ${ }^{2}$ Southern Federal University, 344065 Rostov-on-Don, Russian Federation
}

\begin{abstract}
The article shows the importance of human capital development in the field of management for the effective solution of the problems of modernization of modern education. This article is aimed at identifying specific resources and risks that are reflected in the process of professional development of the Manager today. For the successful activity of the Manager in the field of education, it is important to update his motivation for growth and competence, complex reflection of clusters of individual risks and resources, focus on continuous self-development. The article studies and describes the content characteristics of managers ' ideas about psychological factors that can facilitate or block professional and personal growth. The attention is focused on the role of the education Manager in ensuring effective activity, the level of subjective control, which reflects the degree of internality, autonomy and responsibility for management decisions and the nature of professional activity. It is emphasized that the role of subjective control of the Manager increases in the context of risks of modernization of the modern educational system. Levels of acceptance of information on own resources and risks as bases of modeling of further development are revealed.
\end{abstract}

\section{Introduction}

Modern Russian society, characterized by a tendency to saturation with innovative social and educational projects, new technologies naturally imposes other requirements to the quality of professionalism Manager and its manifestations in the practice of management systems of different orders. In education today the management of human capital development comes to the fore as a basis for maintaining and promoting progress $[1,2,3]$.

Currently, for the successful activity of the Department in the field of education, it is important to update the motivation of growth and competence, reflection of clusters of individual risks and resources, focus on constant self-development. In the context of the resource approach, attention is focused on the fact that productive professional

\footnotetext{
*Corresponding author: tatiananik@list.ru
} 
development depends primarily on how the Manager is personally immersed in this process and is ready for creative transformations of himself and his professional life [4].

The nature and content of the professional development of the Manager in the higher education system is also associated with a personal resource that gives the opportunity to flexibly transform their professional behavior and structure self-development $[5,6,7,8]$.

In a multicultural educational space, the study of multi-level resources and the risks of professional development of a modern education Manager makes it possible to more effectively organize the process of training and retraining of specialists in this field. At different levels of professionalization, the subject of management activity organizes its activity under the influence of diverse attitudes: value-semantic, interactive, subjective, determining the features of decision-making [9, 1011$]$.

Modern conditions impose special requirements on the personal image of the Manager as a significant individual resource productivity management. This is due to the functional image as a certain means of psychological impact on the members of the organization and the social environment for the set of broadcasting models of competent behavior in situations of different meanings and levels of complexity [12].

In the system of determining the success of the innovative Manager can be identified professionally significant qualities: emotional and volitional, intellectual, communicative, forming certain clusters $[2,13]$.

In the modern scientific practice of studying the problems of management in education, a psychological model of social giftedness of a Manager as a resource for his professional development is comprehensively worked out [14].

Interpretation and analysis of psychological research, allows us to identify a group of empirical indicators of professional competence of innovative Manager: high status of cognitive activity; the ability of effective self-presentation in social and professional space, the ability to positive changes in the educational environment, productive functioning, fluency in management techniques; high level of organizational culture; enrichment of the Arsenal of management technologies own innovative creative projects [15].

Innovative management in education today involves mobility, flexibility and creativity, a wide thesaurus of decision algorithms and strategy building. The peculiarity of management in education is determined primarily by the fact that it is aimed at stimulating, organizing and managing the activity of various subjects, positioning leadership qualities and the formation of the ability to create teams for the development and implementation of projects [16].

In psychology, it is proved that the success of professional and personal development is influenced by factors such as: the need for achievement, growth motives and the level of motivation of competence. From the point of view of psychologists, the necessary condition for the effective implementation of the trajectory of professional development of the Manager is an adequate self-assessment of their individual characteristics of resources and risks [17].

The subjective factors that prevent the formation of an adequate developed self-esteem include: deficiencies in the development of professional self-consciousness, limited motives for development and Self-change; insufficient mastery of self-development techniques, self-improvement; low level of interest in the profession, integration of professional Selfconcept, difficulties in reflection, problems of self-control and self-regulation, actualization of unproductive coping strategies, lack of psychological readiness [18].In modern psychology focuses on the fact that for a Manager career aspirations are an expression of orientation to the optimal realization of personal potential and professional competence.

\section{Research methods and techniques}


The study used a set of methods and techniques relevant to the stated problem. The set of psychodiagnostic techniques included such as: test USK (level of subjective control) J. The rotter in the modification of E. F. Bazhina, E. A. Galushkina, L. M. Etkind, M. S. Eminova - test of achievement motivation and motivation failure avoidance; test "strategy of behavior in conflict" by K. Thomas. Expert evaluation of the effectiveness of education managers in professional activities; essay "education Manager: resources and development risks", author's an-ket "Factors of professional development of modern education Manager".

\section{Research result}

In the system of psychological determinants of the effectiveness of professional growth Manager focuses on the module of professionally significant qualities as a developing system. The structure of the system of internal psychological determinants presents various subsystems of characteristics of the subject of management activities of semantic, cognitive, emotional, communicative nature.

The aim of this study was to empirically study the resources and risks of professional development of education Manager, i.e. heads of educational institutions of Rostov-on-don and Rostov region.

The focus of attention in the study was the following positions: the level of subjective control, the degree of motivation of achievements and avoidance of failures, strategy of behavior in conflict and meaningful features of the respondents-managers about resources and risks of professional development in innovative educational practice. In total, 164 managers took part in the study, with more than 5 years of experience in the position.

The effectiveness of the professional activity of the modern education Manager, its development, to a certain extent determined by the level of motivation to achieve successoriented.

The analysis of the results obtained in this study suggests that the motive for success is expressed to a greater extent in $36.3 \%$ of the study, and the motive for avoiding failures in $31.2 \%$, while $32.5 \%$ of managers have these motivational trends are almost balanced, motivational orientations have similar values of severity.

The level of subjective control, which reflects the degree of internality, autonomy and responsibility for the decisions taken and professional activity, plays an important role in the activities of the education Manager, its effectiveness. The role of subjective control increases in innovation management in terms of risks of modernization of educational systems. Given this fact, the study aims to study the degree of internality of education managers, manifested in various spheres of life.

The analysis and generalization of the obtained data demonstrate the peculiarities of subjective control in this sample of respondents - managers.

Identified the following indicators on the scale of internality: more pronounced internality in the field of health, production and Milic-surface relations in the field of achievements. With regard to subjective control over personal and family life, the figures are somewhat lower.

Various social groups with different age, gender, ethnic, social and educational status that participate in joint activities are represented in the professional space of the education Manager. This circumstance produces a close attention to the conflictological competence of the innovative Manager of education and his ability to choose and implement productive strategies of behavior in difficult management situations.

Data analysis shows that the hierarchy of preferred strategies of behavior in conflict is as follows: "cooperation", "compromise", "rivalry", "adaptation", "avoidance". 
The results of the content analysis of the essay "education Manager: resources and development risks" provide an opportunity to systematize the difficulties of education managers. These positions can be qualified as risks of professional development, which can and should be corrected

Reflection of the results of the survey and essay managers allow you to select the hierarchy of the major difficulties that are reflected in their submissions: the deficit model of leadership, lack of knowledge of the techniques of team building and actualization of motivation of development of teachers, staff technology.

In terms of autopsychological competence there are problems associated with selfregulation and self-control of functional and emotional States.

During the survey, psychological effects were identified, which, from the point of view of managers, accompany productive professional development, it is, first of all: empowerment, implementation of personal transformation projects, growth of selfconfidence, positive self-attitude, the acquisition of new spaces of self-presentation, the establishment of new contacts, a clearer structure of time and space of professional life.

The analysis of generalized expert assessments of the experience of managers of educational institutions of Rostov-on-don and Rostov region and the analysis of survey data, allows us to state the psychological risks: insufficient level of competence development; difficulties in understanding and evaluating the productivity of variable algorithms for solving the problem; not resource stereotypes of work with production tasks and personnel; lack of awareness in the field of modern management technologies and the use of the potential of a professional team; lack of knowledge in the field of psychology of management and organizational psychology; limited individual thesaurus of competent ways to effectively resolve crisis situations.

\section{Discussion of the research results}

The results are correlated with the current trend of striving for success and value attitude to high achievements as characteristics of the modern social environment. It should be emphasized that today the desire for competitiveness, consistency and achievements is a socially approved characteristic of the professional. In the field of education - this is especially important, as there is a translation of models of effective behavior in the chain "Manager - teacher - student". Innovative educational space abounds with projects, new formats of work organization, new technologies, testing of which is associated with the focus on success. Here, however, the high status of tension can generate anxiety and anxiety and, as a result, increase the motivation to avoid failure.

It is legitimate to conclude that the data obtained make it possible to note the insufficient level of motivation of achievements, which can be regarded as a motivational risk of productive professional development.

The generalized picture of empirical indicators of motivation intensity can be a projection of the contradiction between the Declaration of the value of creativity, development, high achievements and the real level of competence of the Manager, his individual experience, which provokes uncertainty and generates the effect of "unconfirmed claims". Motivational risks, of course, should be the subject of psychological correction in the overall system of progressive professional and personal growth of the Manager.

The complex of empirical data characterizing the substantial originality of resources and risks of the figure of modern education Manager is obtained by testing and questioning using standardized psychological diagnostic techniques.

The materials of the article are of practical importance for the improvement of professional training and retraining, education managers and the implementation of 
programs of psychological support of productive professional development of managerial personnel.

\section{Conclusion}

As a result of the analysis and typification of the empirical data obtained, it was possible to obtain a certain set of resources and risks of professional development of the modern education Manager, to identify the content of the representations of managers about the determinants of professional and personal growth, reflexive assessment of individual resources and risks in the implementation of progressive development, which allows to construct a personalized request for psychological support of this process. The results of the study of the psychological characteristics of professional development of education managers focus on the activity of the subject of transformation, the severity of the subjective position and motivation achievements. Psychological barriers of professional development relate to personal, emotional, motivational and cognitive spheres.

The possibilities and risks of modern social reality as a matrix of professional and personal growth of an innovative Manager are comprehensively shown. It is necessary to emphasize the importance of psychological technologies aimed at ensuring professional development.

The obtained materials regarding the resources and risks of professional and personal growth can be effectively used in the system of psychological service activities in terms of increasing the effectiveness of psychological support of professional development of innovative education Manager.

Thus, the analysis of empirical results shows the presence of certain resources and risks in ensuring professional development, which are associated with the characteristics of the motivational sphere, subjective control, behavior in a problem situation, the competence of choosing a strategy of behavior in conflict, internality in various spheres of life.

\section{References}

1. A.G. Asmolov, Optics of education: socio-cultural perspectives (Education, Moscow, 2015)

2. E.V. Astapenko, Subjective acmeological determinants in conditions of effective professional activity of managers (Southern federal University, Rostov-on-don, 2011)

3. O.F. Morozov, E. A. Nozdrenko, L. N. Zhukovskaya, S. V. Kostylev, EconomonicalXXI. 3-4-2(158), 61-65 (2016)

4. A.R. Halyava, Education and self-development. 4(42), 251-255 (2014)

5. L.A. Zakirzyanova, Education and self-development. 3(13), 8-13 (2009)

6. O.P. Kuchina, Education and self-development. 3(19), 129-134 (2010)

7. I.V. Taraskina, Integration of education. 20, 82-87 (2016)

8. V.T. Vedeneeva, World economy and international relations. 4, 68-80 (2015)

9. O.A. Eremeeva, Education and self-development. 2(8), 25-30 (2008)

10. Yu.V. Andreeva, Education and self-development. 2(36), 3-11 (2013)

11. E.T. Konyukhova, Siberian pedagogical journal. 14, 327-334 (2008)

12. M. Lukashenko, A. A. Ozhigina, Higher education in Russia. 28, 46-56 (2019)

13. D.N. Misirov, T. N. Shcherbakova, Proceedings of the southern Federal University. 178-185 (2011)

14. A.A. Moscow, Sociological researches. 7(327), 26-36 (2011) 
15. I.L. Bulygin, Psychology personal skills of the Manager of education in the context of refresher training (Russian state professional pedagogical University, Ekaterinburg, 2014)

16. T.N. Shcherbakova Russian psychological journal. 12, 86- 98 (2015)

17. L.M. Vilkova, Russian psychological journal. 6, 77-79 (2009)

18. L.D. Gitelman, E.R. Magaril, M.Ya. Khodorovsky. Economics of the region. 1, 174-184 (2014) 